\title{
PELATIHAN PENGGUNAAN KOMIK MATEMATIKA PADA SISWA SMP
}

\author{
Rosita Dwi Ferdiani ${ }^{1}$, Trija Fayeldi², Tatik Retno Murniasih ${ }^{3}$ \\ 1,2,3 Universitas Kanjuruhan \\ ${ }^{1}$ rositadf@unikama.ac.id, \\ 2trija_fayeldi@unikama.ac.id, \\ ${ }^{3}$ tretnom@unikama.ac.id
}

\begin{abstract}
Mathematics is a subject that is still considered difficult by some students. This is because, mathematics is always associated with calculations, formulas, and graphics. In addition there is material in mathematics that is abstract. So students must imagine something abstract in order to understand the material. For this reason, students need intermediaries who make it easy to understand something abstract. This intermediary is called learning media. Based on interviews with mathematics teachers at MTs Miftahul Ulum Ngembal and PGRI Tutur Islamic Middle School, the procurement of mathematics learning media is still lacking. The learning media used are worksheets. The appearance of worksheets is not very interesting and only contains a summary of material and questions, making students less motivated to learn worksheets. They study when the test will be held. This causes learning outcomes, especially mathematics is still low, with a KKM value of 6.5. Problems faced by MTs. Miftahul Ulum Ngembal and PGRI Tutur Islamic Middle School are: a) Lack of learning media that attracts students' attention. b) Lack of student learning motivation in learning mathematics, especially Linear Equation of One Variable. c) Student learning outcomes are low, namely with KKM 6.5. d) Lack of student understanding of algebra material, especially the system of linear equations of one variable. This is because this material is material that has just been received at the junior high school level. The solution offered is to provide Mathematics Comic Training for students of PGRI Tutur Islamic Middle School and MTs Mifathul Ulum Ngembal. This training aims to increase student learning motivation which will have an impact on student learning outcomes. This training will be held in 2 meetings so as not to disturb the learning and teaching process. In practice, students will be divided into groups. Each group will be given a mathematical comic that contains material about one variable linear equations and questions related to one variable linear equations.
\end{abstract}

Keyword: Training, Mathematical Comics, SingleVariable Linear Equations.

\section{PENDAHULUAN}

Matematika merupakan mata pelajaran yang masih dianggap sulit oleh sebagian siswa. Hal ini sejalan dengan pemikiran Wahyudin (2008:338) yang menyatakan bahwa matematika merupakan mata pelajaran yang sulit dipelajari maupun diajarkan. Hal ini dikarenakan, matematika selalu dikaitkan dengan perhitungan, rumus - rumus, maupun grafik. Selain itu terdapat materi dalam matematika yang bersifat abstrak. Sehingga siswa harus membayangkan sesuatu yang abstrak agar dapat memahami materi tersebut. Untuk itu, siswa membutuhkan perantara yang memudahkan dalam memahami sesuatu yang abstrak tersebut. Perantara inilah yang disebut media pembelajaran.

Peran media dalam pembelajaran sangat penting, khususnya pada pembelajaran matematika. Media pembelajaran ini berperan sebagai alat komunikasi antara pengajar atau sumber informasi dengan siswa yang bertujuan untuk merangsang siswa untuk mengikuti kegiatan pembelajaran secara utuh. ( Kustandi dan Sutjipto, 2011:5). Sehingga dapat meningkatkan motivasi belajar siswa.

Berdasarkan wawancara dengan guru matematika di MTs Miftahul Ulum Ngembal dan SMP Islam PGRI Tutur, pengadaan media pembelajaran matematika masih kurang. Media pembelajaran yang digunakan adalah LKS. Tampilan LKS yang kurang menarik dan hanya berisi ringkasan materi dan soal - soal , membuat siswa kurang termotivasi untuk mempelajari LKS. Mereka mempelajari ketika akan diadakannya tes. Hal ini menyebabkan hasil belajar khususnya matematika masih rendah, dengan nilai KKM sebesar 6.5. Adapun permasalahan yang dihadapi kedua 
sekolah tersebut adalah: a) Kurangnya media pembelajaran yang menarik perhatian siswa. b) Kurangnya motivasi belajar siswa dalam mempelajari pelajaran matematika khususnya pada materi Sistem Persamaan Linier Satu Variabel. c). Hasil belajar siswa rendah yaitu dengan KKM 6.5. d) Kurangnya pemahaman siswa terhadap materi aljabar, khususnya sistem persamaan linier satu variabel. Hal ini disebabkan materi ini merupakan materi yang baru diterima di tingkat SMP.

Solusi yang ditawarkan adalah memberikan Pelatihan Penggunaan Komik Matematika Untuk siswa SMP Islam PGRI Tutur dan MTs Mifathul Ulum Ngembal. Pelatihan ini bertujuan untuk meningkatkan motivasi belajar siswa yang nantinya berdampak kepada hasil belajar siswa. Pelatihan ini akan dilaksanakan dalam 2 kali pertemuan agar tidak mengganggu proses belajar dan mengajar. Dalam pelaksanaannya siswa akan dibagi menjadi beberapa kelompok. Setiap kelompok akan diberikan komik matematik yang berisi tentang materi persamaan linier satu variabel dan soal - soal yang berhubungan dengan persamaan linier satu variabel. Komik ini disusun seperti komik pada umumny, tetapi keunggulan komik ini berisi alur cerita yang berhubungan dengan materi sistem persamaan linier satu variabel. Sehingga siswa dapat membaca komik sambil belajar materi sistem persamaan linier satu variabel. Tampilan komik yang berwarna - warni disertai dengan karakter tokoh dalam komik, membuat siswa tertarik untuk membaca dan mempelajari komi ini. Komik ini disertai soal - soal cerita sehingga siswa dapat memperdalam materi dengan mengerjakan soal - soal tersebut.

\section{METODE}

Berdasarkan uraian pada permasalahan, maka solusi yang ditawarkan antara lain sebagai berkut.

1. Melakukan observasi pada siswa tentang masalah yang dihadapi terkait dengan motivasi belajar siswa terhadap materi sistem persamaan linier satu variabel.

2. Pelatihan media komik, khususnya pada materi sistem persamaan linier satu variabel untuk menambah pemahaman siswa tentang materi sistem persamaan linier satu variabel.

Secara umum alur pelaksanaan kegiatan Pengabdian Masyarakat tersebut dituangkan dalam Gambar 3.1 berikut.

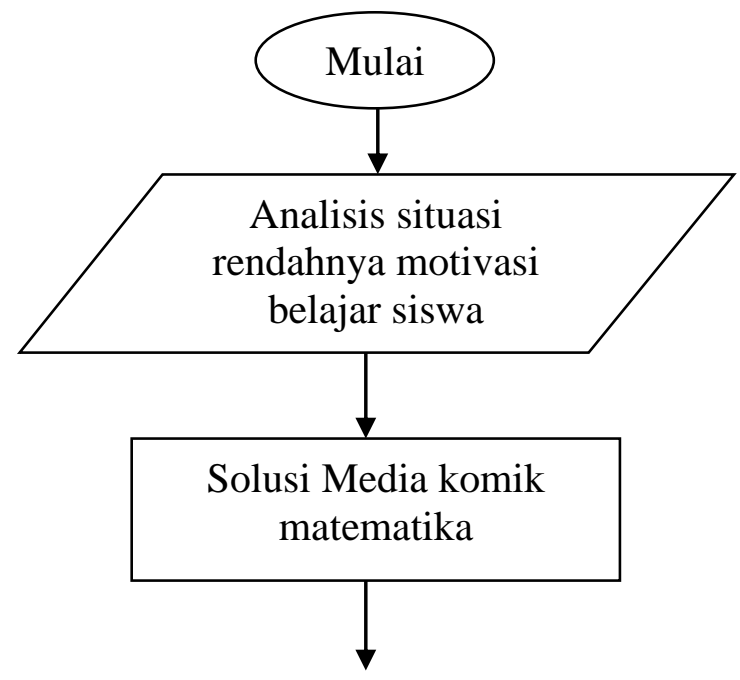




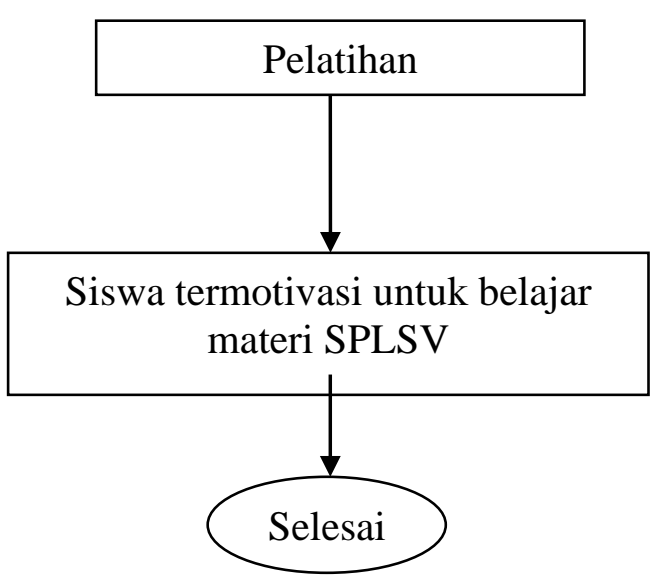

\section{Gambar 1 Alur Pelaksanaan Pelatihan}

Pelaksanan kegiatan ini membutuhkan partisipasi aktif dari sekolah mitra demi kesuksesan program pengabdian dan kelanjutan dari program pengabdian ini.Untuk mendorong partisipasi aktif dari sekolah dalam pelaksanaan program, maka dilakukan beberapa hal sebagai berikut:

a. Pendampingan Mitra.

Pendampingan terhadap sekolah mitra berbentuk diskusi aktif dengan guru mata pelajaran matematika untuk mengatasi permasalahn yang terjadi di sekolah mitra sehingga pelaksanaan pengabdian dapat berjalan lancar.

b. Kehadiran peserta pelatihan menjadi faktor penentu keberhasilan program pengabdian ini.

Target yang ingin dicapai dari kegiatan pengabdian masyarakat ini adalah sebagai berikut.

1) Motivasi belajar siswa terhadap materi sistem persamaan linier satu variabel meningkat.

2) Adanya produk komik matematika pada materi sistem persamaan linier satu variabel.

\section{HASIL KARYA UTAMA DAN PEMBAHASAN}

Kegiatan pengabdian kepada masyarakat ini memberikan manfaat bagi guru serta siswa MTs. Miftahul Ulum Ngembal dan SMP Islam PGRI Tutur. Manfaat yang didapatkan diantaranya siswa memperoleh pembelajaran dengan media manipulatif, berupa buku komik, sehingga pemahaman siswa tentang materi himpunan meningkat. Kegiatan awal dari pengabdian berupa diskusi bersama guru matematika tentang kurangnya media pembelajaran yang menarik perhatian siswa, kurangnya motivasi belajar siswa dalam mempelajari pelajaran matematika khususnya Persamaan Linier Satu Variabel, hasil belajar siswa rendah yaitu dengan KKM 6.5, kurangnya pemahaman siswa terhadap materi aljabar, khususnya sistem persamaan linier satu variabel. Hal ini disebabkan materi ini merupakan materi yang baru diterima di tingkat SMP. 
Tim pelaksana pengabdi mengenalkan kepada guru tentang media komik dalam pembelajaran, cara pembuatannya dan penggunaannya dalam mengerjakan soal sistem persamaan linier satu variabel. Setelah guru paham pembuatan dan penggunaan media komik,

maka media tersebut diperkenalkan kepada siswa MTs. Miftahul Ulum Ngembal dan SMP Islam PGRI Tutur. Observasi awal terhadap siswa diawali dengan tanya jawab untuk mengetahui pemahaman awal siswa tentang materi sistem persamaan linier satu variabel. Setelah itu mulai dikenalkan penggunaan media komik dengan membaca isi komik dan berusaha menjawab soal yang berada di dalam komik. Pengabdi melaksanakan pembimbingan dan pelatihan disesuaikan dengan jadwal pelajaran matematika di sekolah, sehingga tidak menggangu mata pelajaran lain. Materi kegiatan disesuaikan dengan kurikulum yang digunakan MTs. Miftahul Ulum Ngembal dan SMP Islam PGRI Tutur.

Siswa MTs. Miftahul Ulum Ngembal dan SMP Islam PGRI Tutur sangat antusias pada saat pelatihan. Siswa merasa senang dengan adanya pelatihan penggunaan media komik, karena mereka bisa memahami materi sistem persamaan linier satu variabel dengan lebih mudah. siswa dapat membaca komik sambil belajar materi sistem persamaan linier satu variabel. Tampilan komik yang berwarna - warni disertai dengan karakter tokoh dalam komik, membuat siswa tertarik untuk membaca dan mempelajari komi ini. Siswa menginginkan pelatihan media manipulatif untuk materi yang lain dapat dilaksanakan.

Faktor pendukung dari pelatihan media komik matematika pada siswa SMP antara lain:

a. Sekolah menerima dengan baik kehadiran tim pengabdi.

b. Semangat yang tinggi dari siswa untuk mengikuti kegiatan pengabdian.

c. Siswa tertarik menggunakan media untuk menyelesaikan soal-soal tentang sistem persamaan linier dua variabel.

Faktor penghambat dari pelatihan media manipulatif pelatihan media komik matematika pada siswa SMP yaitu

a. Lokasi yang agak jauh dari kampus serta perjalanan melewati jalur macet lalu lintas menjadikan kegiatan tidak bisa dilaksanakan setiap hari.

b. Kesulitan mengatur jadwal antara jadwal matematika di sekolah dengan jadwal tim pengabdi.

Kerjasama dalam pelatihan media komik matematika pada siswa SMP memberi keuntungan bagi tim pengabdi dan sekolah. Bagi tim pengabdi selain untuk aplikasi teori yang dimiliki juga mendapatkan kredit point kinerja pegawai, sedang bagi sekolah akan menambah wawasan siswa dalam mengenal, memahami, dan mengaplikasikan materi himpunan dengan bantuan media manipulatif. Wawasan dan pemahaman siswa tentang materi himpunan meningkat setelah diadakan pelatihan media komik matematika pada siswa SMP

Kemampuan siswa dalam menyelesaikan soal-soal sistem persamaan linier dua variabel meningkat setelah diadakan kegiatan pelatihan. Tim pengabdi memberikan soal untuk diselesaikan siswa. Berdasarkan hasil pekerjaan siswa $87 \%$ siswa MTs. Miftahul Ulum Ngmbal dan $80 \%$ siswa SMP Islam PGRI Tutur dapat menyelesaikan soal-soal sistem persamaan linier dua variabel dengan baik. Berdasarkan evaluasi dapat disimpulkan pemahaman siswa tentang materi himpunan mengalami peningkatan. Siswa juga sangat antusias untuk bertanya tentang materi persamaan linier dua variabel. 


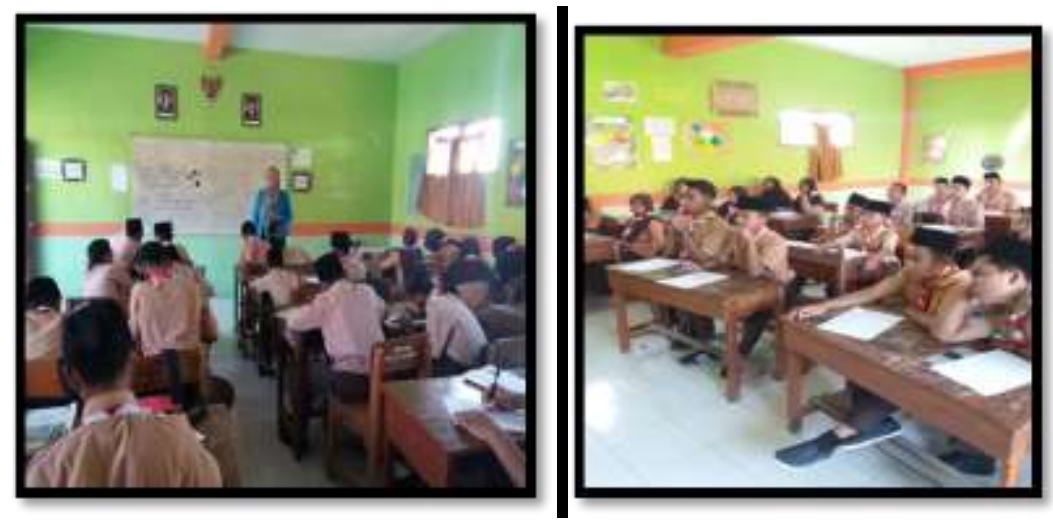

Gambar 2 Pelaksanaan Pelatihan

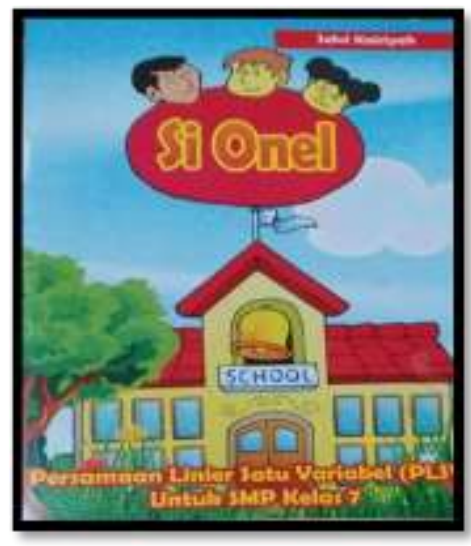

Gambar 3. Media Komik Pada Materi Persamaan Linier Satu Variabel
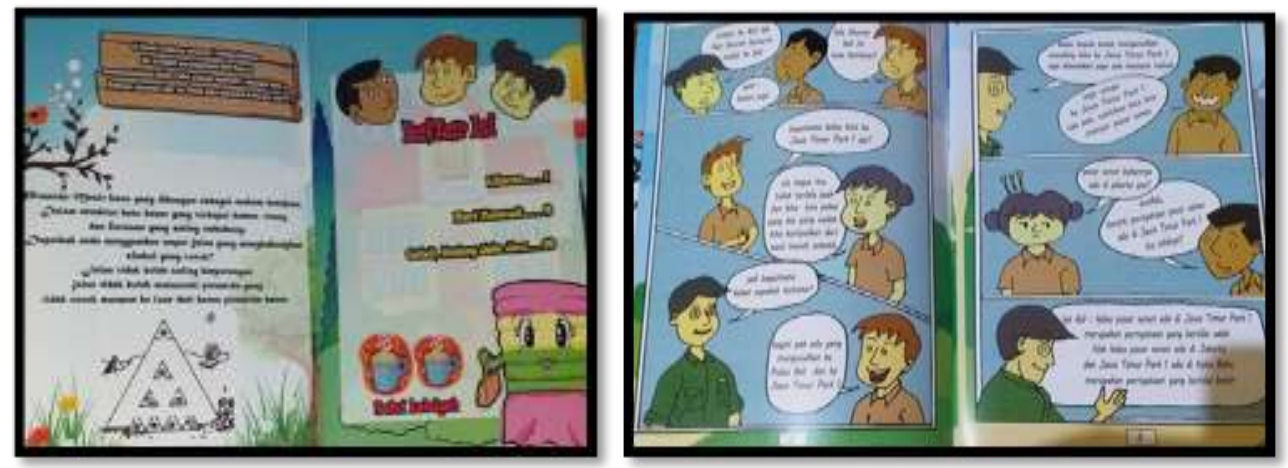

\section{Gambar 4. Bagian isi dari media komik}

Berdasarkan refleksi maka perlu dilakukan kegiatan lanjutan berupa pelatihan yang berkelanjutan untuk materi yang lain sebagai salah satu cara melatih siswa lebih paham tentang berbagai konsep pada mata pelajaran matematika. Pendampingan untuk latihan juga perlu diprogramkan supaya benar-benar memberikan manfaat secara nyata. Kegiatan ini diharapkan akan menambah minat siswa dalam belajar matematika sehingga hasil belajarnya meningkat. 


\section{KESIMPULAN}

Pelaksanaan kegiatan pelatihan media komik matematika pada siswa SMP berlangsung sesuai rencana dan jadwal yang ditentukan yaitu selama 2 bulan dan diikuti oleh seluruh siswa. Meningkatnya pemahaman konsep dan hasil belajar siswa dalam materi sistem persamaan linier dua variabel yang ditandai dengan $87 \%$ siswa MTs. Miftahul Ulum Ngembal dan $80 \%$ siswa SMP Islam PGRI Tutur dapat menyelesaikan soal-soal sistem persamaan linier dua variabel dengan baik.

Guna mendapatkan hasil yang optimal sebaiknya pelatihan dilaksanakan secara berkelanjutan. Sekolah MTs. Miftahul Ulum Ngembal dan SMP Islam PGRI Tutur cukup potensial sebagai tempat pelatihan media manipulatif, sehingga hendaknya LPPM Universitas Kanjuruhan Malang senantiasa menjalin kerjasama tersebut secara berkelanjutan.

\section{DAFTAR PUSTAKA}

Wahyudin. (2008). Pembelajaran dan Model-model Pembelajaran. Bandung: UPI.

Kustandi, Cecep dan Bambang Sutjipto. 2011. Media Pembelajaran; Manual dan Digital. Bogor: Ghalia Indonesia. 